\title{
Study on the Private Enterprises Establishment of Modern Enterprise System
}

\author{
Honghua Qi and Dongming Yu* \\ Shenyang municipal Party School, Shenyang, China;
}

Keyword: Private enterprise; Modern enterprise system; Path

\begin{abstract}
On the modern enterprise system, in addition to the "clear property rights, clear responsibilities, separation of government and enterprise, and scientific management" sixteen words guiding principle, most of the study included only the structure of property rights, the structure of organization, the structure of management. After years of research, the author finds that the content of the modern enterprise system should include all the contents of enterprise production and management, so, it is proposed for the first time from the five plates that are capital structure, governance structure, production structure, innovation structure and benefit structure to study the modern enterprise system. It is a great breakthrough in the research of modern enterprise system theory. On this basis, the author proposes the path of establishment of a modern enterprise system of private enterprises and the government aided path, hope for helpful for private enterprises to establish a modern enterprise system in two aspects both theory and practice.
\end{abstract}

\section{Introduction}

In our country, for the problem of low efficiency and non-separation of government and enterprise in the state-owned enterprises, the term "modern enterprise system" was first proposed in the 1990s. Clear property rights, clear responsibilities, separation of government and enterprise, and scientific management were included in it. From 1990s to beginning of this century, the government, enterprises and academies have all done a lot of research on the modern enterprise system. Most people are interpreting modern enterprise system as a company or shareholding system, this paper argues that this is just a simple understanding and does not explain the full meaning of modern enterprise system. Fundamentally, the essence of establishing a modern enterprise system is to make the structure of property rights clear and reasonable, the production and operation activities more standardized, decision-making and operation more scientific and efficiency, to benefit the long-term development of enterprise[1]. So establishing a modern enterprise system is a enterprises' development strategy, and benefits to enhance enterprise value. In this sense, private enterprises also need to establish a modern enterprise system. The relevant documents issued by Chinese government also fully embodies the problem' attention that private enterprises establish a modern enterprise system.

\section{The General Problems in the China's Private Enterprise System Construction}

Although socialist market economy development for more than 30 years, there are still many problems to be solved in the China's private enterprise system construction:

Property rights system: A large number of small and medium-sized private enterprises are still in the initial stage of unclear property rights, and this problem has not been much changed. In property rights, private enterprises have strong blood kinship and geopolitical nature, and this nature makes private enterprises with a strong patriarchal on the subject. That is, enterprises operation is usually subject to patriarchal rules, rather than market'. Most private enterprises are still solo owner property rights. One of the main reasons behind the private enterprise property right system reform is the high cost of property rights definition.

Structure of governance: Due to the special structure of property right, there is a serious "dominance" structure in private enterprises. In most of family enterprises, family holdings are extremely high, and a considerable part of absolute controlling, equity is too concentrated to supervise and restrain the board of directors and management to accept diversified ownership in a 
wider range.

Management: Ownership and management of many private enterprises did not achieve a reasonable separation, lack of professional and institutionalized management division, and family management' multiple rights structure may lead opacity of rules and conflicts of family interests. Enterprises lack strategic management awareness and measures, "step and step", and have no long-term market competition strategy[2]. In the innovation mechanism, talent introduction and training, cultural construction and other aspects, enterprises are all imperfect.

Relationship between enterprise and government: The majority of private enterprises do not form a benign interaction mechanism in the relationship. When government formulating and implementing policy, private enterprises prefer close personal relationships with government officials to participate the process of policy in order to get government support, so it not only encourages corruption and rent-seeking, but makes enterprises increasingly deviate from the track of development. Establishing a modern enterprise system is an effective way to solve many problems existing in private enterprises[3].

\section{The Full Connotation of Modern Enterprise System}

On the modern enterprise system, in addition to the "clear property rights, clear responsibilities, separation of government and enterprise, and scientific management" sixteen words guiding principle, most of the study included only the structure of property rights, the structure of organization, the structure of management. This paper points out that modern enterprise system is the product of large-scale socialized production and market economy. And modern enterprise system adapts to the needs of modern market economy, to standardize and perfect legal system as the main; investor and enterprise entity bear limited liability, implement corporate governance structure to build strategic framework for improving enterprise value[4]. So modern enterprise system' research include all in production and operation of enterprises: capital structure, governance structure, production structure, innovation structure and benefit structure etc..

\section{Capital Structure.}

Capital structure refers to the source of various capital and their proportional relationship. In a given period of time, the best capital structure makes the weighted average cost of capital lowest, the enterprise value largest, and requires that assets remain in proper flow and the structure is flexible. An effective way to realize capital structure diversified and optimal needs to diversification of property right structure, and shareholding system is the best choice. So this paper regards capital structure as the primary study of modern enterprise system, that is to investigate whether the enterprise implements shareholding system, shareholder composition and proportion of material asset and immaterial assets[5,6]. Realizing diversification of capital structure, determining a reasonable equity proportion and proportion of material asset and immaterial assets, not only help enterprises asset security and forming flexible strategic space, but hedge their risks and achieve long-term development.

\section{Governance Structure.}

Governance structure mainly depends on whether the enterprise's mode of decision-making, financial management and purchasing management realizes reasonable division of labor and clear responsibility of owners, operators and producers. In short, that is how to divide power within enterprise. Governance structure of China adopts "separation of three powers" system, that is, shareholders' meeting, the board of directors or the executive directors and the board of supervisors mastered decision-making power, managerial authority and supervisory power separately. The three organs carry out their duties and restrict each other through checks and balances of power, and ensure enterprise smooth operation. Governance structure is a management and control system, it not only provide all participants' distribution of power and responsibility, such as board of directors, managers, shareholders and other closely connected, but define the rules and procedures that should be followed when making decisions. Good company governance can solve the problems caused by different enterprise interests, and play a decisive role in enterprises' efficient operation and competitiveness. 


\section{Production Structure.}

Production structure mainly depends on production standard of operation, degree of automation, and whether production process needs the external cooperation and the way of cooperation between cooperative enterprise and the enterprise. With the rapid development and convenience of science and technology, information, transportation, modern enterprise production mode have great changes compared with traditional: many enterprises related to the production of enterprises or even across the globe and it means production can in other factory. In other words, production structure of modern enterprises generally includes not only its own production system, but co-production system and supporting enterprises, and sometimes the production related enterprises may be shareholders', to help enterprises achieve stability of supply chain. Reasonable production structure, including production resources' combination and control, has become the key factor that affecting enterprises survival and development.

\section{Innovation Structure.}

Innovation structure mainly depends on the mode of enterprise's technological innovation and management innovation mechanism. Many traditional enterprises survive decades and generations through a product or technology. But faced with the rapid development of technology and fierce competition worldwide, if modern enterprises can not be sustained innovation, they will difficult to develop continuously, so this paper argues that innovation structure is an important content of modern enterprise system's study. An enterprise with a good innovation structure is hard to be eliminated. Innovation structure includes source of its core technology and management innovation mechanism[2]. The sources of core technologies have independent $R \& D$, collaborative $R \& D$, and outsourcing; management innovation mechanism is the key to innovation structure, and more important than above. As long as there are scientific and reasonable management methods, technological innovation will continue, and enterprises will have an endless momentum.

\section{Enterprise Path}

Followed five plates of modern enterprise system, the path of establishing modern enterprise system for private enterprise is sorted out one by one:

\section{Clarify the Capital Structure.}

Most owned and partnership private enterprises' capital structure is unclear, such as assets source, historical value and current value are not clearly defined; most private entrepreneurs do not have the concept of ensuring capital structure security that determine a reasonable proportion of material assets and immaterial assets, proper ratio of liquid assets and fixed assets; partners in a partnership are mostly ambiguous in terms of rights and responsibilities of their assets and liabilities. Lack of clear capital structure leaded to a series of management disorders, so to establish modern enterprise system, we must clarify the capital structure firstly, and find out the enterprise's capital source and proportion. Divided the share each shareholder should be based on value of various assets, whether shareholders into shares with material assets or immaterial assets, and they exercise their power and responsibilities according to share proportion.

\section{Perfect Governance Structure.}

Most owners have decision-making power in private or partnership enterprises' governance, that is, no governance structure and only owner authority. When the enterprise scale is growing and business scope is more widely, owners gradually realize that a person's decision to determine enterprise' affairs is too risky and want to change the condition, but decentralization such as hire professional managers often encounter obstacles of family and entrepreneurial team. Only by establishing modern enterprise system and perfecting governance structure can we solve these problems. According to requirements of shareholding enterprise, set up shareholders meeting, board of directors, board of supervisors system, execute the corresponding system and earnestly implement corresponding powers and duties. In order to ensure investors interests, the major problems in the operation should be fully discussed by the board of directors and made by the shareholders; the board of supervisors is responsible for supervising the decision-making activities of the board and the management, and the enterprise form a corporate governance structure that is responsible, coordinated and effectively balanced. 


\section{Transform Production Structure.}

Modern enterprise system must be scientific and reasonable in the production structure. Scientific and reasonable, it is not only the cost and efficiency, but the stability and sustainability of the production structure. With development of globalization, the procurement chain and production collaboration units can spread all over the world, the production can be able to gather around the world supporting enterprises by modern technologies, information technology at any time and place, which continuously integrate the most advanced and active production factors in and out of the production line. And these are not hard to do as long as companies are willing. However, enterprises should not only focus on immediate interests, consider cost and efficiency, but the stability and sustainability of the production structure.

\section{Upgrade Innovation Structure.}

As mentioned above, innovative structure includes technological innovation and management innovation mechanism. Most private enterprises pay more attention to technological innovation and ignore the construction of management innovation mechanism, but the latter is a higher level of innovation. In the era of increasing speed of innovation in products, technologies and knowledge, maximizing profit as the sole theme is one of the major causes of enterprise failure and sustainability of growth is becoming an important issue of modern enterprises. Therefore, establishing scientific and reasonable innovation mechanism, enterprises can be truly invincible.

Building management innovation mechanism, first of all, requires owners, operators, and managers to raise awareness, update idea, use scientific and standardized management model to become innovative managers. Second, enterprises may adopt competitive pressure and equity incentive method and combine personal value realization, social responsibility and other consciousness training to stimulate the entrepreneurial innovation power, because it is not only the technical innovation that determines enterprise survival, system, process, and the small innovation is equally important. Finally, forming a long-term mechanism to promote innovation, stimulating innovation awareness and encouraging innovation, enhancing innovation capability and turning management thoughts into motivation, support and trust, make enterprises full of vigor and vitality of innovation.

\section{Standardize Benefit Structure.}

Most private enterprises pay more attention to the economic benefits and ignore the social benefits. They are more concerned about the distribution of earnings between shareholder and enterprise development, but neglect the distribution between enterprises and society. Partnership will generally tend to the former while distributing interests between shareholders and enterprise development, and this is due to the emotional factors or mentality of just obtained some achievements easily satisfied. Some private entrepreneurs occasionally participate in public donations, but most are entrepreneurs' personal behavior, not enterprise behavior, and it does not belong to the modern enterprise system. To establish modern enterprise system, private enterprises must standardize benefit structure, regulate interest distribution between shareholders and enterprise development, and standardize enterprises' social responsibility. Enterprises should be driven by a one-sided pursuit of the interests to realize social responsibility and achieve economic, environmental and social coordinated development. In the present business environment, most business development programs carry out ethical assessments and environmental impact analysis, so social responsibility policy is no longer the question of whether implement or not and is how to effectively implement. Enterprises should divide a certain percentage of profit based on their annual earnings, and invest in public welfare fixedly and continuously.

\section{The Auxiliary Path of Government}

Private enterprises should independently decide whether establish modern enterprise system, and the role of the government is to encourage, guide and support. The long-term historical culture and institutional mechanism and other practical problems have led many private entrepreneurs have an incomplete understanding of modern enterprise system, so governments should give full attention and adequate guidance to the establishment of a modern enterprise system. For enterprises with the 
intention of establishing modern enterprise system, government can cultivate model for their imitation, and introduce professional consulting organization to solve the problem of establishing modern enterprise system, and give guidance during building. Finally, government can set up an evaluation mechanism to evaluate the modern enterprise system and issue certificate.

Specific ideas are as follows:

\section{Guidance and Training in Early Stage.}

In the early stage, the government's role is to arouse private entrepreneurs' enthusiasm and enthusiasm for establishing modern enterprise system. At this stage, many private enterprises know a little about modern enterprise system, and keep a hesitant attitude on establishing modern enterprise system, so the relevant departments should actively organize modern enterprise system knowledge training, choose model enterprise which has good practice effect of the modern enterprise system, and encourage private entrepreneurs to learn its theory and practice experience. By guiding and training, entrepreneurs understand the modern enterprise system from simple enterprise system level to the strategic level, and recognize that establishment of modern enterprise system is an important way to enhance core competitiveness and enterprises value.

\section{Introducing and Guiding in Medium Stage.}

When entrepreneurs began to realize the need to establish modern enterprise system and want to carry out this work actively, in second stage, government's role is to help entrepreneurs solve problems that who are qualified. The departments should grasp enterprises' situation accurately and guide the qualified to establish modern enterprise system timely, and make operation structure reasonable and value system scientific and transparent. "Qualified" means not all enterprises are suitable for introducing modern enterprise system immediately, because the enterprise with a certain size will soon generate operational advantage by introducing modern enterprise system, and the small will increase cost and reduce efficiency in stages. Before the establishment of modern enterprise system, small enterprises must make adequate preparations, and problem of adjustment should be taken into consideration. In the process of introducing modern enterprise system, the government should also give larger enterprises the necessary and preferential policy, to offset the problem of management costs increasing and efficiency reducing in the initial stage.

\section{Tracking and Evaluation in Late Stage.}

After enterprises basically completed modern enterprise system construction, the government should keep track of the implementation, research and response to difficult enterprises timely, encourage and propagate enterprises of implementation smoothly, set up a typical for the follow-up enterprises to learn. Internal and external environment of enterprise is dynamic, so modern enterprise system is also in dynamic. The system imply keeping up with time in itself, and it needs to be reconstructed dynamically, so the government put forward improvement suggestions to the enterprise by real-time tracking, keen observation and clear judgment.From government's perspective, supervising enterprises to establish modern enterprise system is a systems engineering that benefit for private enterprise survival, social ecology, economic development and social progress, and its significant. This paper argues that it's necessary for government to establish assessment and tracking system and form corresponding index, to evaluate the operation effect of private enterprises' modern enterprise system.

\section{Acknowledgements}

This article is an achievement of the key research project of the Central Party School. The project is "Research on the relationship between government and market in resource allocation under the background of Northeast revival".

\section{References}

[1] W.X. Li, The Efficiency Dilemma and Transcendence of Modern Enterprise System, (Ph.D., Jilin University, China 2004). (In Chinese)

[2] L.Y. Mao, New Thoughts on Modern Enterprise System, Economic Review, 11(2012)12-19. (In 


\section{Chinese)}

[3] H.J. Zhou. Research on Modern Enterprise System Sinicization. (Ph.D., Chinese Academy of Social Sciences, China 2014). (In Chinese)

[4] L.Y. Mao, Managerial Revolution in Economic Transition-Evaluation on MBO in the Reform of State-owned Enterprise, Journal of Shanghai University of Finance and Economics, 3(2005). (In Chinese)

[5] C.Z. Xu and D.M. Zhang, A main enterprise theories' review of the new institutional economics school, Jianghan Tribune, 7(2004)5-8. (In Chinese)

[6] D.M. Yu, Influence of Regional Cultural Diversity of New Ventures Creation, Technoeconomics \& Management Research, 11(2014). (In Chinese) 